\title{
Hukkakauran itävyyden säilyminen lehmän ruoansulatuskanavassa
}

Heikkilä, T. ${ }^{1)}$, Saarisalo, E. ${ }^{1,5)}$, Khalili, H. ${ }^{1)}$, Jalli, H. ${ }^{2)}$, Köylijärvi, S. ${ }^{3)}$, Poikulainen, J. ${ }^{3)}$, VallivaaraPasto, R. ${ }^{3)}$ ja Jaakkola, S. ${ }^{4}$

${ }^{1)}$ Maa- ja elintarviketalouden tutkimuskeskus MTT / Kotieläintuotannon tutkimus, 31600 Jokioinen

${ }^{2)}$ Maa- ja elintarviketalouden tutkimuskeskus MTT / Kasvintuotannon tutkimus, Kasvinsuojelu, 31600 Jokioinen, etunimi.sukunimi@mtt.fi

${ }^{3)}$ Elintarviketurvallisuusvirasto EVIRA, PL 111, 32201 Loimaa, etunimi.sukunimi@evira.fi

${ }^{4)}$ Helsingin yliopisto, Maataloustieteiden laitos, PL 28, 00014 Helsingin yliopisto, etunimi.sukunimi@helsinki.fi

${ }^{5)}$ Nykyinen osoite: Maa- ja metsätalousministeriö, Elintarvike- ja terveysosasto, PL 30, 00023 Valtioneuvosto, etunimi.sukunimi@mmm.fi

\section{Tiivistelmä}

Hukkakaura on erityisesti viljanviljelyä ja siementuotantoa haittaava yksivuotinen, helposti leviävä ja vaikeasti hävitettävä rikkakasvi. Laki hukkakauran torjunnasta (185/2002) määrittelee toimenpiteet, joilla hukkakauraa torjutaan ja estetään sen leviäminen. Hukkakaurayksilöitä sisältävältä alueelta peräisin olevaa kotieläinten lantaa ei saa kuljettaa, säilyttää tai käsitellä siten, että siitä voi aiheutua hukkakauran leviämisen vaara. Tässä tutkimuksessa selvitettiin, voivatko hukkakauran siemenet säilyä itämiskykyisinä lehmän ruoansulatuskanavassa, jolloin lanta aiheuttaisi hukkakauran leviämisriskin.

Vuosina 2005 - 2007 kerätyt hukkakauran siemenet yhdistettiin yhdeksi eräksi, josta määritettiin itävyys. Ruokintakoe tehtiin MTT:n koe-eläintallilla Jokioisilla neljällä Ay-lehmällä, joiden keskimääräinen maitotuotos oli $27,3 \mathrm{~kg} / \mathrm{pv}$. Lehmät saivat vapaasti esikuivattua timotei-nurminadan ensimmäisestä sadosta muurahaishappopohjaisella säilöntäaineella tehtyä pyöröpaalisäilörehua ja $13 \mathrm{~kg} / \mathrm{pv}$ rakeistettua väkirehua (ohra-melassileike-rypsipuriste-kivennäinen). Hukkakauran siemeniä annettiin 200 g kullekin lehmälle kerta-annoksena väkirehun seassa aamuruokinnan yhteydessä. Sen jälkeen kerättiin ja punnittiin jokaiselta lehmältä erikseen kaikki sonta seitsemän päivän aikana 12 tunnin erinä alkaen hukkakauran antamisesta. Sonta pestiin vesisuihkulla tiheän (Ø $1 \mathrm{~mm})$ seulan päällä, jonka jälkeen pestyä sontaa laitettiin veteen pienissä erissä ja etsittiin hukkakauran siemenet. Hukkakauran siementen annettiin kuivua avoimella alustalla huoneenlämmössä ennen itävyysmääritystä. Itävyysmääritykset tehtiin Eviran Tutkimus- ja analytiikkaosaston Kasvianalytiikkayksikön laboratoriossa Loimaalla ja rehujen koostumus- ja laatuanalyysit MTT:n Eläinravitsemusryhmän sekä maitoanalyysit MTT:n biotekniikka- ja elintarviketutkimuksen laboratorioissa Jokioisilla.

Lehmille syötettyjen hukkakauran siementen itävyys oli $87 \%$. Sonnassa erittyneiden hukkakauran siementen määrä ja itävien siementen osuus väheni sitä mukaa, mitä kauemmin ne viipyivät lehmän ruoansulatuskanavassa. Ruokinnan jälkeen ensimmäisen vuorokauden aikana hukkakauran siemeniä erittyi sonnassa $17 \%$ koko viikon aikana löytyneestä kokonaismäärästä ja niiden itävyys oli $34 \%$. Kahden vuorokauden (0-48 tuntia) aikana ruokinnasta oli erittynyt jo $71 \%$ hukkakauran siemenistä, joiden itävyys oli $15 \%$. Kahden vuorokauden jälkeen ruokinnasta hukkakauran siementen itävyys oli hävinnyt lukuun ottamatta yhtä lehmää, jolta erittyi yksi itävä siemen vielä neljännen vuorokauden aikana. Hukkakauran itävyys väheni $87 \%$ kulkiessaan lehmän ruoansulatuskanavan läpi. Sonnassa erittyi $14 \%$ syödystä hukkakauran siemenien määrästä ja itävistä siemenistä $1,8 \%$. Viikon aikana neljän lehmän sonnasta (1,3 tonnia) löytyi hukkakauran siemeniä yhteensä 4604 kappaletta, joista itäviä oli $504 \mathrm{kpl} \mathrm{eli} 11 \%$. Lanta aiheuttaa siten selvän hukkakauran leviämisriskin, jos rehu sisältää itäviä hukkakauran siemeniä. Tilojen välisessä rehukaupassa sekä lantaa vastaanotettaessa on syytä varmistaa tilan/lohkon hukkakaurattomuus. Ennaltaehkäisy on ensiarvoisen tärkeää hukkakauran leviämisen estämisessä uusille alueille.

Asiasanat: Hukkakaura, Avena fatua, itävyys, lehmä, ruoansulatus, sonta 


\section{Johdanto}

Hukkakauran (Avena fatua L.) jyvä on väriltään ruskea tai harmaa, tyvestä maljamainen ja karvainen ja jokaisessa tuleentuneessa jyvässä on voimakas kierteinen, polveikas vihne (Evira 2009a). Tähkylässä on kahdesta kolmeen siementä. Yksi hukkakaurayksilö voi tuottaa 10-1000 siementä (Pessala 1983). Hukkakaura on erityisesti viljanviljelyä ja siementuotantoa haittaava yksivuotinen, helposti leviävä ja vaikeasti hävitettävä rikkakasvi (MMM 2007, Evira 2009b). Sitä on kulkeutunut Suomeen ulkomailta tuodussa rehu-, mylly- ja siemenviljassa ainakin vuodesta 1921, ja vuodesta 1923 lähtien Valtion siementarkastuslaitos on todennut hukkakauraa myös kotimaisissa siemennäytteissä (Hilli 1959). Tällä hetkellä hukkakauran saastuttama peltopinta-ala on noin $14,5 \%$ koko pelto-alasta eli yli 328000 hehtaaria (Evira 2009b). Hukkakaura vie elinvoimaa muilta kasveilta ja alentaa satoa (MMM 2007, Evira 2009b). Hukkakauran torjunta lisäsi kevätvehnäsatoa 9-15 \% (445-700 kg) käsittelemättömään kasvustoon verrattuna (Junnila 2008). Hukkakauran jyvät ovat vahvakuorisia ja keveitä, jonka vuoksi niillä ei ole suurta arvoa karjanrehuna (Hilli 1959).

Laki hukkakauran torjunnasta (185/2002) ja sen nojalla annettu Maa- ja metsätalousministeriön asetus (326/2002) määrittelevät toimenpiteet, joilla torjutaan hukkakauraa ja estetään sen leviäminen. Laissa todetaan muun muassa, että hukkakaurayksilöitä sisältävältä alueelta peräisin olevaa viljaa, siemeniä, heinää, kasvijätettä, akanoita, viljan ja siemenien puhdistus- ja lajittelujätteitä, kotieläinten lantaa, maa-ainesta ja maanparannusaineita ei saa kuljettaa, säilyttää tai käsitellä siten, että siitä voi aiheutua hukkakauran leviämisen vaaraa.

Tässä tutkimuksessa selvitettiin, voivatko hukkakauran siemenet säilyä itämiskykyisinä kuljettuaan lehmän ruoansulatuskanavan läpi, jolloin lanta voi aiheuttaa hukkakauran leviämisriskin. Tieto on oleellinen hukkakauran leviämisriskin arvioinnissa ja leviämisen ehkäisemisessä.

\section{Aineisto ja menetelmät}

Ruokintakokeessa käytettiin yksityisten maatilojen ohrapelloilta vuosina 2005-2006 kokoviljan säilöntäkokeissa (Saarisalo ym. 2008) kerättyjä itävimpiä hukkakauran siemeneriä ja 1.8.2007 kerättyjä hukkakauran siemeniä, jotka sekoitettiin yhdeksi eräksi, josta määritettiin itävyys ja koostumus.

Ruokintakoe tehtiin 11.-18.9.2007 MTT:n koe-eläintallilla Jokioisilla neljällä Ay-lehmällä, joista yksi oli yhden kerran ja muut 2-3 kertaa poikineita. Lehmille annettiin vapaasti timoteinurminadan ensimmäisestä sadosta tehtyä esikuivattua pyöröpaalisäilörehua, joka oli säilötty AIV 2 Plus-säilöntä-aineella (76 \% muurahaishappoa, 5,5\% ammoniumformiaattia, 18,5\% vettä, Kemira Oyj) 2,8 litraa paalia kohti. Väkirehuna lehmät saivat $13 \mathrm{~kg} / \mathrm{pv}$ rakeistettua tilaseosta, joka sisälsi $50 \%$ ohraa, $20 \%$ melassileikettä, 28 \% Öpex-rypsipuristetta ja $2 \%$ kivennäistä. Rehuista kerättiin näytteet punnituksen yhteydessä ja maidosta neljältä lypsykerralta.

Hukkakauran siemeniä annettiin $200 \mathrm{~g}$ kullekin lehmälle kerta-annoksena väkirehun seassa aamuruokinnan yhteydessä klo 6 . Sen jälkeen kerättiin ja punnittiin jokaiselta lehmältä erikseen kaikki sonta seitsemän päivän aikana 12 tunnin jaksoissa alkaen hukkakauran antamisesta (klo 6-18 ja 18-6). Sonta pestiin vesisuihkulla tiheän seulan (Ø $1 \mathrm{~mm})$ päällä, jonka jälkeen pestyä sontaa laitettiin pienissä erissä isolle valkealle lautaselle veteen ja etsittiin hukkakaurat. Kultakin lehmältä erittyneet hukkakauran siemenet annettiin kuivua avoimella alustalla huoneenlämmössä ennen itävyysmääritystä.

Itävyysmääritykset tehtiin Eviran Tutkimus- ja analytiikkaosaston Kasvianalytiikkayksikössä Loimaalla. Rehujen koostumus- ja käymislaatuanalyysit sekä maidon urea tehtiin MTT:n Eläinravitsemusryhmän laboratoriossa sekä maitoanalyysit (rasva, proteiini, laktoosi) MTT:n biotekniikka- ja elintarviketutkimuksen laboratoriossa Jokioisilla.

\section{Tulokset ja tulosten tarkastelu \\ Rehujen koostumus ja laatu sekä lehmien syönti ja tuotostiedot}

Esikuivattu pyöröpaalisäilörehu oli koostumukseltaan ja käymislaadultaan hyvää: kuiva-aine $470 \mathrm{~g} / \mathrm{kg}$, tuhka $84 \mathrm{~g} / \mathrm{kg}$ ka, raakavalkuainen $160 \mathrm{~g} / \mathrm{kg}$ ka, neutraalidetergenttikuitu (NDF) $559 \mathrm{~g} / \mathrm{kg} \mathrm{ka}$ ja D-arvo eli sulavan orgaanisen aineen määrä $688 \mathrm{~g} / \mathrm{kg}$ ka. Säilörehu oli vähän käynyttä: pH 4,61, sokeri 72 $\mathrm{g} / \mathrm{kg}$ ka , maito-, etikka- ja voihappo $36,9 \mathrm{ja} 0,2 \mathrm{~g} / \mathrm{kg}$ ka ja ammoniumtypen osuus kokonaistypestä 51 $\mathrm{g} / \mathrm{kg}$ N. Väkirehussa oli tuhkaa $63 \mathrm{~g} / \mathrm{kg}$ ka, raakavalkuaista $189 \mathrm{~g} / \mathrm{kg}$ ka, tärkkelystä $305 \mathrm{~g} / \mathrm{kg} \mathrm{ka}$ ja NDF-kuitua $242 \mathrm{~g} / \mathrm{kg}$ ka.

Lehmät söivät säilörehua keskimäärin $9,5 \mathrm{~kg}$ ka ja väkirehua $11,6 \mathrm{~kg} \mathrm{ka} / \mathrm{pv}$, yhteensä kuivaainetta $21,1 \mathrm{~kg} / \mathrm{pv}$. Karkearehu-väkirehusuhde oli 45:55. Maitotuotos oli keskimäärin 27,3 kg/pv, jossa 
oli rasvaa 40,0, valkuaista 36,8 ja laktoosia 49,6 g/kg sekä ureaa $23,9 \mathrm{mg} / 100 \mathrm{ml}$. Lehmien elopaino oli keskimäärin $601 \mathrm{~kg}$ vaihdellen välillä 531-673 kg.

Hukkakaura sisälsi hyvään viljeltyyn rehukauraan verrattuna vähemmän tärkkelystä ja enemmän tuhkaa, kuitua ja ligniiniä muistuttaen ravintoarvoltaan hyvin huonoa kauraa, ns. katokauraa (Taulukko 1). Hukkakauran 100 jyvän $(\mathrm{n}=8)$ paino oli 2,5 g ja sen perusteella laskien kullekin lehmälle syötettiin 200 grammassa 8000 hukkakauran siementä.

Taulukko 1. Hukkakauran siementen koostumus ruokintakokeessa verrattuna kahteen eri laatuiseen viljeltyyn rehukauraan.

\begin{tabular}{|c|c|c|c|c|c|c|c|}
\hline & Tuhka & $\begin{array}{c}\text { Raaka- } \\
\text { valkuainen }\end{array}$ & $\begin{array}{c}\text { Raaka- } \\
\text { rasva }\end{array}$ & $\begin{array}{c}\text { Tärkke- } \\
\text { lys }\end{array}$ & $\mathrm{NDF}^{1)}$ & $\mathrm{ADF}^{2}$ & Ligniini \\
\hline & \multicolumn{7}{|c|}{ 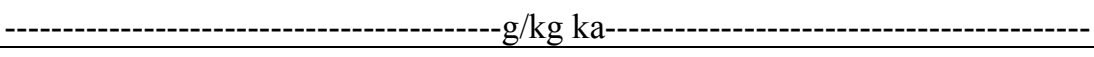 } \\
\hline Hukkakaura & 40 & 129 & 73 & 362 & 407 & 191 & 36 \\
\hline \multicolumn{8}{|l|}{ Viljelty rehukaura } \\
\hline Kaura, 61 kg/hl ${ }^{3)}$ & 28 & 103 & 72 & 476 & 288 & 123 & 28 \\
\hline Kaura, $33-43 \mathrm{~kg} / \mathrm{hl}^{3)}$ & 31 & 123 & 61 & 328 & 434 & 194 & 34 \\
\hline
\end{tabular}

1) $\mathrm{NDF}=$ neutraalidetergenttikuitu, ${ }^{2)} \mathrm{ADF}=$ happodetergenttikuitu,${ }^{3)}$ MTT:n "Katoviljakoe", hyvän kauran valkuaispitoisuus oli poikkeuksellisen pieni vuonna 1987 Jokioisilla (Heikkilä, julkaisematon)

\section{Hukkakauran itävyys}

Lehmille syötettyjen hukkakauran siementen itävyys oli 87 \% ( $n=538$ siementä). Ensimmäiset hukkakauran siemenet löytyivät sonnasta jo puolen vuorokauden kuluessa ruokinnasta, jolloin niiden itävyys oli suurimmillaan. Sonnassa erittyneiden hukkakauran siementen määrä ja itävien siementen osuus väheni sitä mukaa, mitä kauemmin ne viipyivät lehmän ruoansulatuskanavassa (Taulukko 2 ja Kuvio). Ensimmäisen vuorokauden aikana hukkakauran siemeniä erittyi $17 \%$ koko viikon aikana löydetystä kokonaismäärästä ja niiden itävyys oli $34 \%$. Kahden vuorokauden (0-48 tuntia) aikana oli erittynyt jo $71 \%$ kaikista erittyneistä hukkakauran siemenistä ja niiden itävyys oli $15 \%$. Neljäntenä vuorokautena löytyi vielä yksi itävä hukkakauran siemen. Siihen mennessä oli erittynyt $95 \%$ löydetyistä hukkakauran siemenistä. Siemeniä erittyi vielä senkin jälkeen vähentyen koko ajan kokeen loppuun saakka, mutta ne eivät olleet itäviä. Ruoansulatusprosessin aikana hukkakauran itävyys väheni 87 \% syötetyn itävyydestä. Tämä johtui todennäköisesti ruoansulatusnesteiden ja märehtimisen siemeniä ja alkiota vahingoittavasta vaikutuksesta.

Taulukko 2. Sonnassa erittyneiden hukkakauran siementen määrä ja niiden itävyys viikon aikana puolen vuorokauden jaksoissa yhteensä neljältä lehmältä.

\begin{tabular}{cccc}
\hline $\begin{array}{c}\text { Aika } \\
\text { ruokinnasta } \\
\text { vrk }\end{array}$ & $\begin{array}{c}\text { Hukkakauran siemeniä } \\
\text { sonnassa yhteensä } \\
\mathrm{kpl}\end{array}$ & $\begin{array}{c}\text { Hukkakauran } \\
\text { siementen itävyys } \\
\%\end{array}$ & $\begin{array}{c}\text { Itävyyden väheneminen } \\
\text { syötetyn itävyydestä } \\
\%\end{array}$ \\
\hline $0-0,5$ & 10 & 40 & 54 \\
$0,5-1,0$ & 767 & 34 & 61 \\
$1,0-1,5$ & 1722 & 13 & 85 \\
$1,5-2,0$ & 792 & 1 & 99 \\
$2,0-2,5$ & 414 & 0 & 100 \\
$2,5-3,0$ & 341 & 0 & 100 \\
$3,0-3,5$ & 158 & 0 & 100 \\
$3,5-4,0$ & 192 & 0,5 & 99 \\
$4,0-4,5$ & 139 & 0 & 100 \\
$4,5-5,0$ & 30 & 0 &, \\
$5,0-5,5$ & 19 & 0 &, \\
$5,5-6,0$ & 7 & 0 &, \\
$6,0-6,5$ & 8 & 0 &, \\
$6,5-7,0$ & 3 & 0 &, \\
$7,0-7,5$ & 2 & 0 & $\%$ \\
\hline
\end{tabular}


Viikon aikana neljän lehmän sonnasta (1304 kg) löytyi yhteensä 4604 hukkakauran siementä, joista itäviä oli $504 \mathrm{kpl}$ eli $11 \%$. Keskimäärin lehmää kohti erittyi 1151 hukkakauran siementä viikossa, joista itäviä oli $126 \mathrm{kpl}$. Annetusta hukkakauramäärästä erittyi sonnassa $14 \%$ ja syötetyistä itävistä siemenistä itäviä oli sonnassa $1,8 \%$. Lehmien välillä oli eroa hukkakauran siementen erittymismäärissä ja siementen itävyydessä. Itävyys vaihteli 7 ja 15 prosentin välillä. Ensikkolehmällä hukkakauran siemeniä erittyi sonnassa vähiten, mutta niiden itävyys oli korkein.

Lanta aiheuttaa edellä olevien tulosten perusteella hukkakauran leviämisriskin, jos eläimen rehu sisältää itäviä hukkakauran siemeniä, sillä yksikin itävä siemen ja kehittyvä kasvi voi tuottaa satoja uusia siemeniä. Tässä kokeessa ei tutkittu lannan varastoinnin vaikutusta itävyyden säilymiseen.

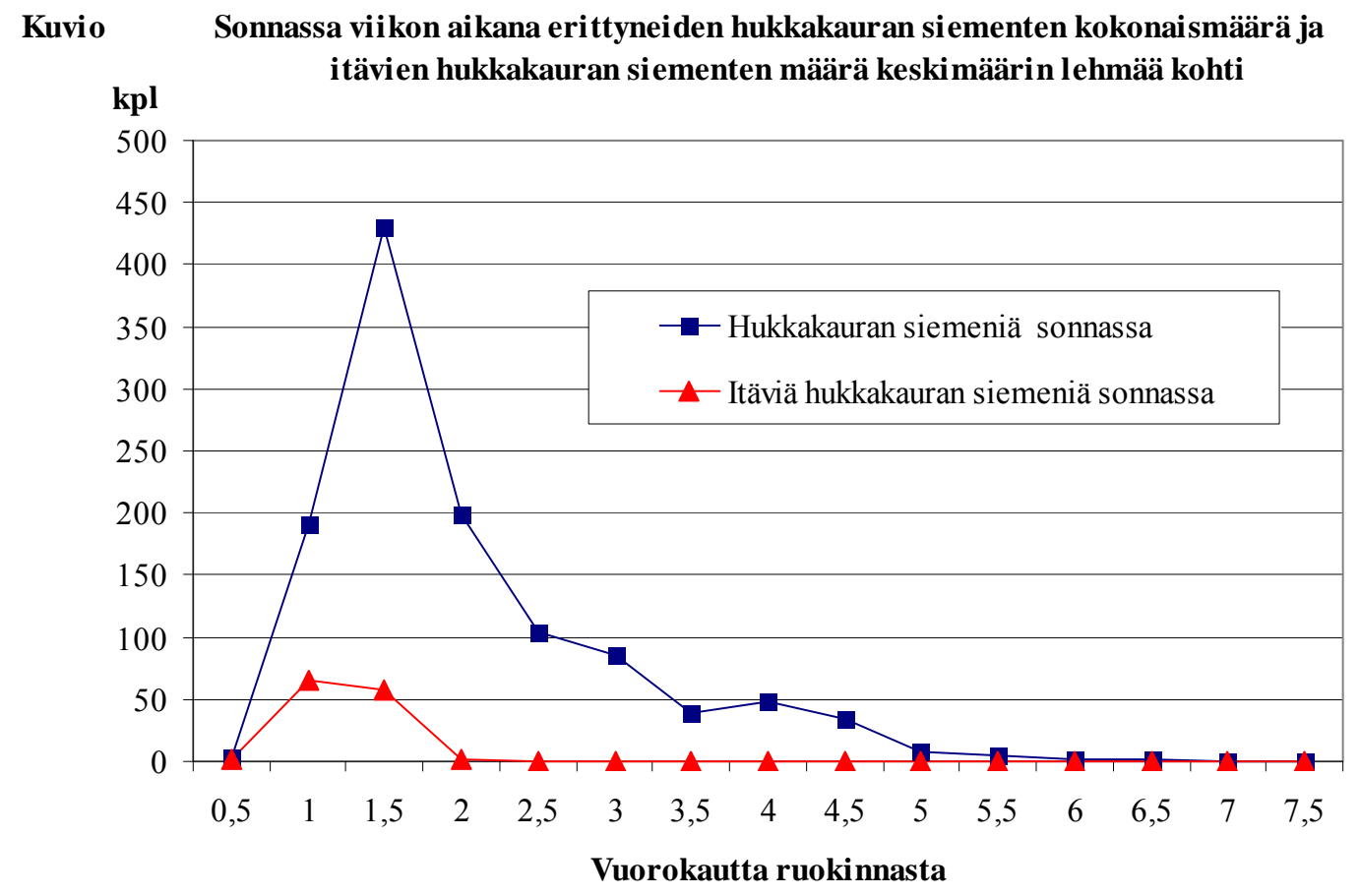

\section{Tutkimustuloksia muualta}

Syötetyn hukkakauran siementen elinkyky ja itävyys vaikuttavat itävyyden säilymiseen sen läpäistessä ruoansulatuskanavan. Atkesonin ym. (1934) tutkimuksissa lehmillä sinimailasheinä-viljaruokinnalla hukkakauran itävyyden ollessa ruokittaessa $43 \%$, oli itävyys 47 tunnin jälkeen sonnassa vain $0,25 \%$. Kun syötetyn hukkakauraerän itävyys oli $74 \%$, oli sonnassa erittyneiden hukkakauran siemenien itävyys $10 \%$. Sen sijaan ruoansulatuksen $(47 \mathrm{~h})+$ sonnan kolmen kuukauden varastoinnin jälkeen olkilantana hukkakauran itävyys oli hävinnyt. Tutkittuja siemeniä oli kuitenkin vain 25 , joten tulosta ei voi pitää luotettavana. Vasikalle syötetystä kahdesta tuhannesta hukkakauran siemenestä taimettui seitsemän siementä turvelannassa 11 kuukauden aikana kasvihuoneessa kasvatettaessa (Thurston 1952) ja seuraavana vuonna iti vielä kolme siementä lisää (Thurston 1953). Kirk ja Courtney (1972) tutkivat härillä normaalien ehjien ja naarmutettujen sekä kuorittujen hukkakaurojen itävyyden säilymistä ruoansulatuskanavassa. Suurin osa hukkakauran siemenistä erittyi kolmen vuorokauden aikana, jonka jälkeen ei enää löytynyt itäviä siemeniä. Eniten erittyi kuorittuja siemeniä ja vähiten ehjiä, mutta niiden itävyydessä ei ollut merkitsevää eroa. Kaikkiaan syötetyistä hukkakauran siemenistä erittyi sonnassa $15 \%$, joista $22-28 \%$ oli itäviä. Koko syötetystä hukkakauramäärästä erittyi itävinä sonnassa maksimissaan $12 \%$. Härkien karsinaan sisällä siroteltujen hukkakauran siemenien itävyys oli neljän viikon jälkeen $27 \%$, mutta 13 viikon päästä ei löytynyt enää itäviä hukkakauroja. Ulkona olevan lantakasan keskellä hukkakauran siemenet menettivät nopeammin itävyytensä, mutta kasan pohjalla ja reunoilla oli itäviä siemeniä vielä 12 viikon jälkeen, mutta 21 viikossa itävyys oli hävinnyt. Kirkin (1975) mukaan hukkakauran siemenistä menetti elinkykynsä 90-100 \% kulkiessaan ruoansulatuskanavan läpi, ja enimmillään siemenet pysyivät elossa 51 vuorokautta naudan lietelannassa matalassa lämpötilassa $\left(7,5^{\circ} \mathrm{C}\right)$. Hukkakauran siemenet kuolivat sian lietteessä kuudessa viikossa, mutta lihanaudan kuivemmassa lietelannassa oli vielä muutama itämiskykyinen siemen sen jälkeen (Courtney 1973). 
Riederin (1966) tutkimusten mukaan hukkakaura osoittautui vastustuskykyiseksi, eikä sen siemenet menettäneet itävyyttään lietelannassa 40 päivässä, mutta 3-4 kuukauden varastoinnin jälkeen itämiskykyisiä siemeniä ei löytynyt yhtään tai vain hyvin vähän. Itävyyden häviämisen syynä hän piti lietelannan ammoniakin toksista vaikutusta, sillä siemenien käsittely puhtaalla vastaavan väkevyisellä ammoniakkiliuoksella tuhosi hukkakauran siementen itävyyden.

\section{Johtopäätökset}

Tutkimus vahvisti aiemmat havainnot, että hukkakauran siemenet voivat läpäistä naudan ruoansulatuskanavan itävinä, joskin ne menettävät suurimman osan itävyydestään. Tässä tutkimuksessa hukkakauran itävyys väheni $87 \%$ rehunsulatuksen aikana lehmän ruoansulatuskanavassa. Vaikka sonnassa erittyvien hukkakauran siementen itävyys oli vain $11 \%$, muodosti lanta kuitenkin selvän hukkakauran leviämisriskin. Yksikin itävä hukkakauran siemen voi saastuttaa puhtaan alueen, jos siitä kasvavaa kasvia ei havaita ajoissa. Tilojen välisessä rehukaupassa sekä lantaa vastaanotettaessa ja lannanlevityssopimuksia tehtäessä on syytä varmistaa tilan/lohkon hukkakaurattomuus. Hukkakauran leviämisen estämisessä on ensiarvoisen tärkeää ennaltaehkäistä uusien alueiden saastunta. Jo saastuneen hukkakaura-alueen torjunta tuottaa aina ylimääräistä työtä, kustannuksia ja taloudellisia menetyksiä.

\section{Kirjallisuus}

Atkeson, F.W., Hulbert, H.W. \& Warren, T.R. 1934. Effect of bovine digestion and of manure storage on the viability of weed seeds. Journal of the American Society of Agronomy 26: 390-397.

Courtney, A. D. 1973. Wild oat seed - its survival in bedding, farmyard manure and slurry. Agriculture in Northern Ireland 47: 435-436.

Evira 2009a. Hukkakauran havaitseminen kasvustosta. Viitattu 27.11.2009.

http://www.evira.fi/portal/fi/kasvintuotanto_ja_rehut/siemenet/hukkakaura/havaitseminen_ja_tunnistaminen/

Evira 2009b. Hukkakauran torjunta on rahanarvoinen ratkaisu. Viitattu 27.11.2009.

http://www.evira.fi/attachments/kasvintuotanto_ja_rehut/siemenet/siemenohjeet/hukkakauran_torjunta_on_rahan arvoinen_ratkaisu_uusin.pdf

Hilli, A. 1959. Hukkakauran (Avena fatua L.) esiintymisestä Suomessa. Suomen maataloustieteellisen seuran julkaisuja, Acta Agralia Fennica 94: 299-315.

Junnila, S. 2008. Herbicides in cereals : Control of Avena fatua and Elymus repens in cereals : Evaluation of Axial 50 EC in tank mix with BLW herbicides in wheat, Kylmäkoski. In: Edited by Tellervo Ruoho and Leena Ruokonen. Trial Report, Herbicides, MTT Agrifood Research Finland, Jokioinen 2008, p. 55-68.

Kirk, J. \& Courtney, A.D. 1972. A sudy on the survival of wild oats (Avena fatua) seeds buried in farm yard manure and fed to bullocks. In: Proceedings $11^{\text {th }}$ British Weed Control Conference. p. 226-233.

Kirk, J. 1975. The survival and transport of seeds of wild oat (Avena fatua L.) in agricultural situations. Thesis, Queen's University Belfast. UK. Abstract.

Laki hukkakauran torjunnasta 185/2002. http://www.finlex.fi/fi/laki/alkup/2002/20020185

MMM 2007. Selvitys hukkakauralainsäädännön vaikutuksista 2007. Työryhmämuistio mmm 2007:18. 12 s.

Helsinki 2007. ISBN 978-952-453-350-8, ISSN 0781-6723.

http://www.mmm.fi/attachments/mmm/julkaisut/tyoryhmamuistiot/2007/5tFetMb8q/trm2007_18_Hukkakaurase lvitys_lopullinen_versio.pdf

MMM asetus hukkakauran torjunnasta 326/2002. http://www.finlex.fi/fi/laki/alkup/2002/20020185

Pessala, B. 1983. Kaikin keinoin hukkakauraa vastaan. Käytännön Maamies 6: 22-24.

Rieder, R. 1966. Der Einfluss des Schwemmistes auf die Unkrautverbreitung und die Anwendung der Tetrazolium-Methode bei Unkrautsamen. Dissertation. Landwirtschaftlichen Hochschule Hohenheim. 119 p.

Thurston, J.M. 1952. Biology of wild oats. Report for 1951, Rothamsted experimental station. p. 67-68.

Thurston, J.M. 1953. Biology of wild oats. Report for 1952, Rothamsted experimental station. p. 68-69.

Saarisalo, E., Heikkilä, T., Jalli, H., Poikulainen, J., Köylijärvi, S. \& Jaakkola, S. 2008. Hukkakauran siementen itävyyden säilyminen kokoviljasäilörehussa. Teoksessa: Anneli Hopponen (toim.). Maataloustieteen Päivät 10.-11.1.2008, Suomen maataloustieteellisen seuran tiedote 23: $6 \mathrm{~s}$.

http://www.smts.fi/mpol2008/index_tiedostot/Esitelmat/es085.pdf 